(C) [2007] IEEE. Reprinted, with permission, from Dou, Yiping; Guo, Youguang; Zhu, Jianguo; Lu, Hai Yan. 2007, Effect Of Armature Reaction Of A Permanent-magnet Claw Pole SMC Motor', IEEE Transactions On Magnetics, vol. 43, no. 6, pp. 25612563. This material is posted here with permission of the IEEE. Such permission of the IEEE does not in any way imply IEEE endorsement of any of the University of Technology, Sydney's products or services. Internal or personal use of this material is permitted. However, permission to reprint/republish this material for advertising or promotional purposes or for creating new collective works for resale or redistribution must be obtained from the IEEE by writing to pubs-permissions@ieee.org. By choosing to view this document, you agree to all provisions of the copyright laws protecting it. 


\title{
Effect of Armature Reaction of a PM Claw Pole SMC Motor
}

\author{
YiPing Dou, YouGuang Guo, Senior Member, IEEE, Jian Guo Zhu, Senior Member, IEEE, \\ and HaiYan Lu
}

\begin{abstract}
Finite element method enables an accurate analysis for the study on effects of armature reaction in electromagnetic devices, particularly those with complex structures and threedimensional (3-D) magnetic flux paths. This paper investigates the effects of armature reaction on the parameters and performance of a permanent magnet (PM) claw pole motor with soft magnetic composite (SMC) core, based on the magnetic field analysis using the 3-D nonlinear time stepping finite element method. The current in the stator winding produces a magnetic field, which interacts with the air gap field generated by the rotor magnets. Consequently, the airgap flux density profile against the rotor position produced by the rotor magnets deviates, so does the back electromotive force. Since the stator field also changes the local saturation level of the magnetic core, the winding inductance varies with both the rotor position and stator currents. The inclusion of these effects in terms of parameter variations in the motor model is important for accurate performance analysis. On the other hand, the pattern of inductance against the rotor position and stator currents can be employed to predict effectively the rotor position at standstill and low speeds for robust sensorless control. The parameter computations are verified by experimental results on the PM claw pole SMC motor prototype.
\end{abstract}

Index Terms-Armature reaction, PM claw pole motor, SMC motor, finite element magnetic field analysis, winding flux, inductance.

\section{INTRODUCTION}

$\mathrm{S}_{\mathrm{a}}^{\mathrm{o}}$ OFT MAGNETIC COMPOSITE (SMC) materials possess a number of advantages over the traditional electrical steels, such as magnetic isotropy and very low eddy current loss. Therefore, SMC materials are suitable for application of electromagnetic devices with complex structures and threedimensional (3-D) magnetic flux paths, e.g. claw pole and transverse flux motors [1]. In these machines, the magnetic field distribution is complicated, and 3-D numerical techniques like finite element analysis (FEA) are required to determine accurately the motor parameters and performance.

To investigate the application potential of SMC in electrical

Manuscript received October 31, 2006, revised January 3, 2007.

Y. P. Dou is with the Faculty of Electric Engineering and Automation, Nanjing Normal University, Nanjing, Jiangsu, 210042, China (e-mail: douyiping@njnu.edu.cn).

Y. G. Guo and J. G. Zhu are with the Faculty of Engineering, University of Technology, Sydney, PO Box 123, Broadway, NSW 2007, Australia (e-mails: youguang@eng.uts.edu.au, joe@eng.uts.edu.au).

H. Y. Lu is with the Faculty of Information Technology, University of Technology, Sydney, NSW 2007, Australia (email: helenlu@it.uts.edu.au). machines, a three-phase three-stack permanent magnet (PM) claw pole motor with SMC stator core has been developed by the authors, as illustrated in Fig. 1 [2]. The motor employs an external rotor with three arrays of PMs on the inner surface of the yoke, and an internal stator with three phases stacked axially. Each phase has a simple concentrated coil placed between two SMC claw pole disks. The three stacks are circumferentially shifted to each other by $120^{\circ}$ electrical. The major motor parameters and dimensions include $20 \mathrm{PM}$ poles, stator outer diameter of $80 \mathrm{~mm}$, effective axial length of 93 $\mathrm{mm}$, and main airgap of $1 \mathrm{~mm}$. The motor has successfully operated with a brushless dc (BLDC) scheme, delivering a power of $500 \mathrm{~W}$ at $1800 \mathrm{rpm}$.

This paper aims to investigate the effects of armature reaction on the parameters of the claw pole SMC motor, including the winding flux, back electromotive force (emf) and inductance. The patterns of these parameters against the rotor position are important for accurate simulation of the motor performance. In addition, the inductance pattern, as a function of rotor position and stator currents, may provide an effective method for detecting the rotor position at standstill and low speeds, which is crucial for the start-up and low speed performance of robust sensorless control schemes. The parameter computations agree with the experimental results.

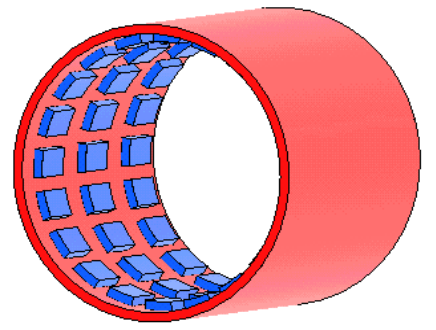

(a)

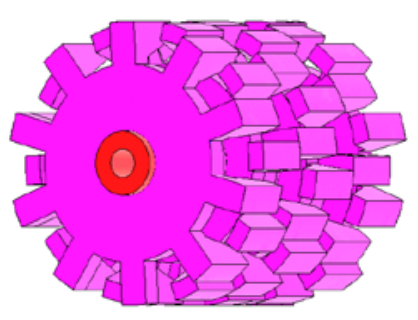

(b)
Fig. 1. Magnetically relevant parts of the PM claw pole SMC motor: (a) Rotor, (b) Stator.

\section{MOTOR OPERATION WITH BLDC CONTROL}

The model of a PM synchronous motor under BLDC control scheme is given as:

$v_{j}=r_{j} i_{j}+d \lambda_{j} / d t+e_{j}, \quad j=a, b, c$

$\lambda_{j}=\sum_{k=a}^{c} L_{j k} i_{k}$ 
$T_{e m}=\left(\sum_{j=a}^{c} e_{j} i_{j}\right) / \omega_{r}+T_{c o g}$

$J \frac{d \omega_{r}}{d t}=T_{e m}-T_{L}-\delta \omega_{r}$ and $\frac{d \theta_{r}}{d t}=\omega_{r}$

where $v_{j}, r_{j}, i_{j}, \lambda_{j}, e_{j}$ are the voltage, resistance, current, flux linkage and back emf (generated by rotor PMs) of the $j$-th phase winding, respectively, $L_{j k}=\lambda_{j} / i_{k}$ is the apparent inductance, $T_{e m}$ the electromagnetic torque, $T_{c o g}$ the cogging torque, $J$ the inertial of rotary parts, $\omega_{r}$ the rotor speed, $T_{L}$ the load torque, $\delta$ the friction coefficient, and $\theta_{r}$ the rotor angle.

As the flux linkage of a stator phase winding is a function of rotor position and stator currents, the second term of (1) can be expanded as

$$
\frac{d \lambda_{j}}{d t}=\sum_{k=a}^{c} \frac{\partial \lambda_{j}}{\partial i_{k}} \frac{d i_{k}}{d t}+\frac{\partial \lambda_{j}}{\partial \theta_{r}} \frac{d \theta_{r}}{d t}=\sum_{k=a}^{c}\left(L_{j k}^{\prime} \frac{d i_{k}}{d t}+\frac{d L_{j k}}{d \theta_{r}} i_{k} \omega_{r}\right)
$$

where $L_{j k}^{\prime}=\partial \lambda_{j} / \partial_{k}$ is the incremental inductance.

Substituting (5) into (1), the voltage equation of the $j$-th phase winding becomes

$v_{j}=r_{j} i_{j}+\sum_{k=a}^{c}\left(L_{j k}^{\prime} \frac{d i_{k}}{d t}+\frac{d L_{j k}}{d \theta_{r}} i_{k} \omega_{r}\right)+e_{j}$

To accurately and effectively predict the motor performance, the simulation model should take into account the variations of key parameters such as $\lambda, e, L, L^{\prime}$ and $T_{\text {cog }}$, with respect to rotor position or time [3]. The parameter variations are caused by the structural saliency and magnetic saturation, as well as the armature reaction.

\section{EFFECTS OF ARMATURE REACTION}

The variation profiles of the motor parameters versus rotor position or time can be accurately obtained from a series of 3D non-linear time-stepping magnetic field FEA solutions [4]. In this paper, the effects of armature reaction are investigated by comparing the parameters with and without stator currents.

Under the condition of the optimum BLDC control, the stator current is in phase with the back emf, i.e. lagging the PM flux (defined as the flux of one phase winding generated by the rotor PMs) by $90^{\circ}$ electrical. The fundamental of the stator current can be expressed as

$i=\sqrt{2} I_{r m s} \sin \theta$

where $I_{r m s}$ is the $r m s$ value of the stator current (4.1A for fullload), $\theta=P \theta_{r}$ the rotor angle in electrical radian, and $P$ the number of pole-pairs. The zero rotor position lies where the claw poles line up with the rotor PMs.

Fig. 2 illustrates the curves of PM flux with respect to the rotor angle (in electrical degrees) at no-load, half-load and full-load, respectively. Under the influence of the load (stator current), the saturation of the magnetic circuit and the PM flux deviate from those at no-load.

To consider the effects of saturation, a two-step technique is employed. Firstly, a non-linear magnetic field analysis is performed with the excitations of both rotor PMs and armature currents, and the permeability in each element is stored. Then, a linear analysis is conducted with the stored permeabilities and the PM excitation only, so that the PM flux can be worked out. Through discrete Fourier transformation [4], it is found that the magnitude of fundamental component of PM flux, as well as the back emf and the developed torque, decreases by about 3.3\% from no-load to full-load.

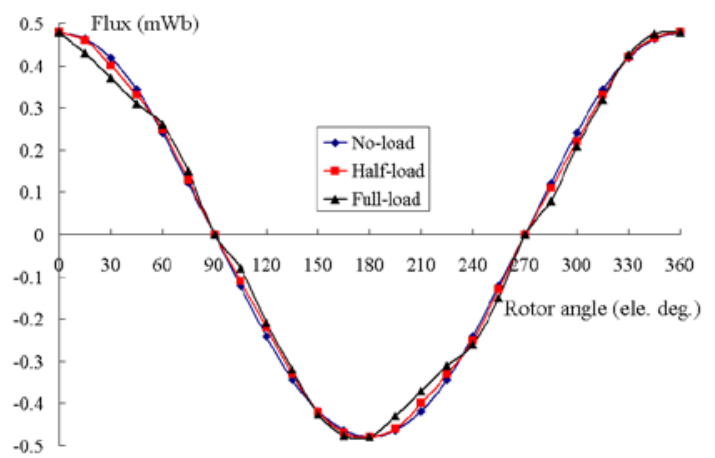

Fig. 2. Per-turn PM flux versus rotor angle

Fig. 3 shows the computed apparent and incremental selfinductance of one phase winding with the effects of armature currents. Again, the two-step technique is applied. Firstly, a non-linear analysis is performed with the rotor PMs and stator currents, and both the apparent and incremental permeabilities of each element are stored, which correspond to $B$ (flux density) $/ H$ (field strength) and $\Delta B / \Delta H$ at the operating point $(B, H)$ of the nonlinear magnetization curve, respectively. Secondly, the PMs are "switched off", and a linear analysis with a current $i$ in the phase winding and the stored permeabilities is conducted to find out the magnetic co-energy, $W_{f}^{\prime}$. Note that the stored apparent permeability should be used for apparent inductance computation and the incremental permeability for incremental inductance. Then the winding inductance can be calculated by the energy method as

$L=2 W_{f}^{\prime} / i^{2}$

It can be seen that the armature reaction affects the inductances and this should be included in the simulation model for accurate prediction of motor performance. Since the three stacks are almost magnetically independent, the mutual inductance can be ignored.

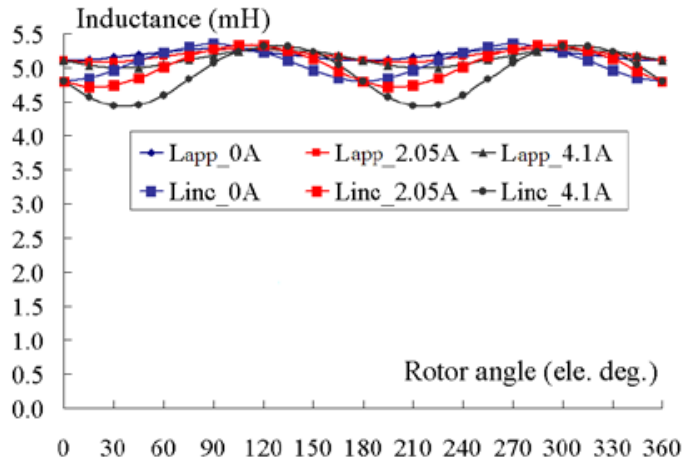

Fig. 3. Apparent and incremental self-inductance of one phase winding 
When the motor operates in the steady state, its magnetomotive force $(\mathrm{mm} f)$ generated by the armature currents, or the resultant $\mathrm{mmf}$ generated by both armature currents and rotor PMs, leads or lags the rotor $m m f$ by a fixed angle. Referred to the rotor, the armature current can be seen as a DC at a specified load. Therefore, the inductance pattern versus different armature currents and rotor positions are very useful information for the design of high performance control schemes, e.g. the direct torque control. Fig. 4 plots the computed incremental inductance of the phase winding against rotor position $\left(0^{\circ}\right.$ to $360^{\circ}$ electrical at the interval of $\left.15^{\circ}\right)$ and stator DC bias current (0 to $4 \mathrm{~A}$ with $1 \mathrm{~A}$ interval). These data, in combination with the interpolation technique, could provide a useful look-up table for the control scheme of the motor, as well as the motor performance simulation by the phase variable model outlined in Section II.

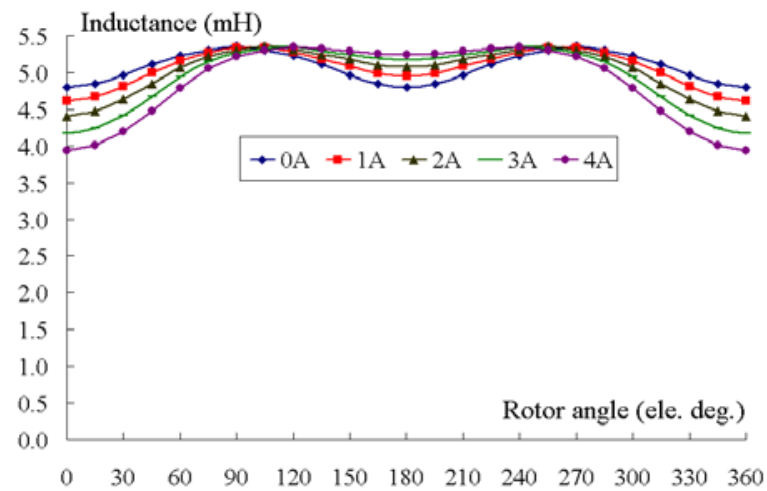

Fig. 4. Computed incremental self-inductance with DC bias in stator winding

\section{INDUCTANCE MEASUREMENT}

To validate the computation, the winding inductance is measured using the common V-A method. When the rotor is fixed at a given position, a small ac current $\left(I_{1}=0.2 \mathrm{~A}\right.$, $f_{1}=500 \mathrm{~Hz}$ ) is fed into a phase winding and the applied voltage $V_{1}$ is measured. The self-inductance is then obtained by

$L_{1}=\sqrt{\left(V_{1} / I_{1}\right)^{2}-R_{1}^{2}} /\left(2 \pi f_{1}\right)$

where $R_{1}$ is the resistance of the phase winding.

Fig. 5 shows the measured inductances at different rotor positions. For comparison, the computed inductances at noload are plotted in the figure. As shown, the computed incremental inductance agrees well with the measurements. Some error may be due to the measuring current, which causes a small loop in the vicinity of the saturation point in the B-H curve. Another possible reason is the eddy current caused by the measuring current. Ideally, the measuring current should be as small as possible but the reading error could be large.

Fig. 6 illustrates the measured inductances with biasing DC currents $(0 \mathrm{~A}, 2 \mathrm{~A}$, and $4 \mathrm{~A})$ in the phase winding. The computed incremental inductance is also plotted, showing that the computation agrees in general with the measurement. The average errors are $4.15 \%, 4.18 \%$ and $5.16 \%$ for stator currents of $0 \mathrm{~A}, 2 \mathrm{~A}$ and $4 \mathrm{~A}$, respectively.

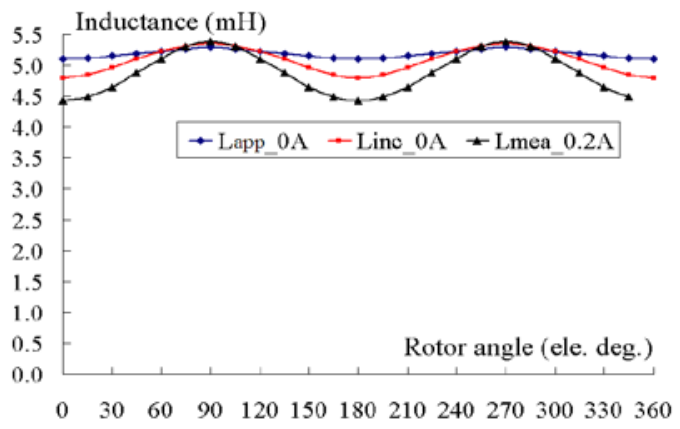

Fig. 5. Computed and measured inductances without armature current

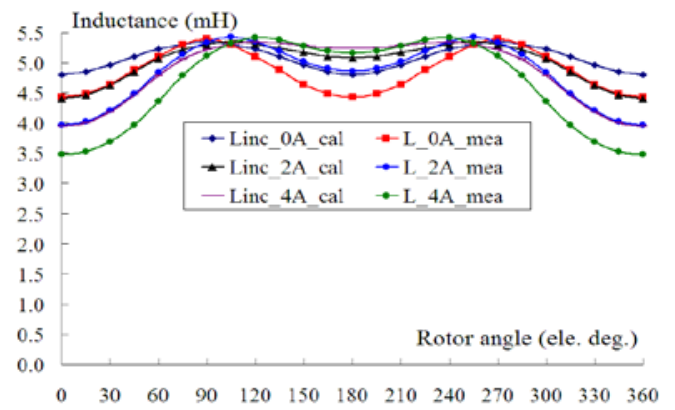

Fig. 6. Computed and measured inductances with DC bias current

\section{CONCLUSION}

The paper investigated the effect of armature reaction on the parameters of a three-phase three-stack PM claw pole motor with SMC stator using 3-D non-linear time-stepping magnetic field analysis. Due to the structural saliency and magnetic saturation, major motor parameters such as winding flux, back emf and inductance are the function of rotor position. Furthermore, the armature reaction also influences the patterns of the parameters, and this should be investigated and included in the simulation model for accurate prediction of motor performance. The inductance computation is verified by the measurement on the motor prototype.

The design of the 3-D flux motor has considered SMC's unique properties such as magnetic isotropy and very low eddy current; the latter is also advantageous with respect to armature reaction which might cause excessive eddy current loss if a laminated core were used.

\section{REFERENCES}

[1] Y. G. Guo, J. G. Zhu, P. A. Watterson, and W. Wu, "Comparative study of 3-D flux electrical machines with soft magnetic composite core," IEEE Trans. Ind. Applicat., vol. 39, no. 6, pp. 1696-1703, Nov. 2003.

[2] Y. G. Guo, J. G. Zhu, P. A. Watterson, and W. Wu, "Development of a claw pole permanent magnet motor with soft magnetic composite stator," Australian J. of Electrical \& Electronic Eng., vol. 2, no. 1, pp. 21-30, 2005.

[3] O. A. Mohammed, S. Liu, and Z. Liu, "A phase variable model of brushless dc motors based on finite element analysis and its coupling with external circuits," IEEE Trans. Magn., vol. 41, no. 5, pp. 15761579, May 2005.

[4] Y. G. Guo, J. G. Zhu, and H. Y. Lu, "Accurate determination of parameters of a claw pole motor with SMC stator core by finite element magnetic field analysis," IEE Proceedings - Electri. Power Appl., vol. 153, no. 4, pp. 568-574, July 2006. 